\title{
On the Provision of Unemployment Insurance when Workers are Ex-ante Heterogeneous
}

\author{
Avihai Lifschitz \\ Tel Aviv University \\ Ofer Setty \\ Tel Aviv University \\ Yaniv Yedid-Levi \\ Interdisciplinary Center (IDC) Herzliya
}

This Draft: October 2018

\begin{abstract}
Labor market outcomes demonstrate considerable variation between and within skill groups. We construct a general equilibrium model with incomplete markets and exogenous differences that matches these facts. We study the role of exogenous heterogeneity in choosing the optimal replacement rate and the maximum benefit for an unemployment insurance (UI) system. The optimal average replacement rate is $54 \%$, compared to $10 \%$ in a model without the features of exogenous heterogeneity. The relatively generous choice in our model is due to the redistributive role of UI - a manifestation of two elements. First, workers who are unemployed more often receive positive net transfers from the UI system because they draw resources more frequently. Second, the existence of a cap makes UI benefits progressive. Our main result holds even in the presence of a generous progressive taxation system.
\end{abstract}

JEL Classification: : D52, E21, J63, J64, J65, C68.

Keywords: Heterogeneous agents, Search and Matching, Incomplete markets, Unemployment Insurance, Redistribution.

\footnotetext{
*Previously titled: "Who Cares about Unemployment Insurance?" We thank Paul Beaudry, Tobias Broer, Moshe Hazan, Aspen Gorry, Nir Jaimovich, Sebastian Koehne, Per Krusell, Toshihiko Mukoyama, Itay Saporta-Eksten, Henry Siu, David Weiss, Stephen Zeldes and seminar participants for very helpful comments. Correspondence: Avihai Lifschitz, Tel Aviv University, E-mail: avihai.lifschitz@ hotmail.com. Ofer Setty, Tel Aviv University, E-mail: ofer.setty@gmail.com. Yaniv Yedid-Levi, Interdisciplinary Center (IDC) Herzliya, E-mail: yaniv.yl1@gmail.com. Setty's research is supported by the Israel Science Foundation (Grant No. 418/11). Yedid-Levi thanks the Social Sciences and Humanities Research Council of Canada for financial support.
} 


\section{Introduction}

It is well documented that labor market outcomes vary substantially between and within skill groups. For instance, Heathcote, Perri, and Violante (2010) document an average college wage premium for men of $80 \%$. It is also known that there exist a substantial variation in wages even when controlling for education and other observable characteristics. In addition, according to CPS data for 1996 - 2014, the average unemployment rate for male college graduates is $2.8 \%$, while that of high-school dropouts is $8.7 \%$, indicating that lower skilled workers face higher unemployment risk.

In this paper we study the effect of these heterogeneity features on the optimal design of an unemployment insurance (UI) system. The analysis is based on a general equilibrium model with incomplete markets, search frictions, ex-ante skill heterogeneity, and individual productivity shocks. The model generates heterogeneity in unemployment rates and dispersed wage and asset distributions.

Our main quantitative finding is that a model with these dimensions of exogenous heterogeneity calls for a generous UI system with an effective replacement rate of 50\%, more than five times as large as the one implied by a model without exogenous heterogeneity. The interpretation of this result revolves around the redistribution of resources between high wage and low wage workers. Specifically, variation in income generates consumption differences between workers. The utilitarian welfare criterion that we use favors equality hence a policy maker in our model associates more dispersion with a stronger incentive for redistribution. Indeed, a key insight of our analysis is that it is possible to use the UI system for redistribution.

Such redistribution occurs either when there are differences in unemployment rates among workers, or when the UI policy includes a potentially binding cap on unemployment benefits. The former implies that certain types of workers draw resources from the UI system more frequently then others. The latter generates a degree of progressively in UI benefits such that the effective replacement rate is higher for lower wage workers.

The analysis builds upon a recent model by Krusell, Mukoyama, and Şahin (2010) (henceforth KMS) that has two key elements. First, unemployment in the model is endogenously determined by a search and matching friction as in Diamond (1982), Mortensen (1982), and Pissarides (1985) (DMP). Second, as in Bewley (undated), Huggett (1993), and Aiyagari (1994) (BHA) workers can self-insure only via risk free assets, and are subject to a borrowing constraint. This implies that workers cannot perfectly insure their idiosyncratic unemployment risk, and that in equilibrium 
there is endogenous heterogeneity in asset holdings. KMS assume that all workers are ex-ante homogeneous and face no exogenous idiosyncratic shocks hence they abstract from issues of heterogeneity in productivity and unemployment risk.

To analyze the consequences of such heterogeneity we add two dimensions of exogenous heterogeneity. First, we assume that the population is divided into skill types that permanently differ in their unemployment rates and expected productivity level. Second, we allow for idiosyncratic productivity shocks within these types. Those two sources of exogenous heterogeneity play a major role in generating a realistic distribution of wages and wealth in the economy.

We carefully design two transfer programs in our model. First, the UI system includes in addition to the typical replacement rate used in the literature a cap on the benefit. While this realistic feature of the model is redundant when the wage distribution is degenerate, this additional instrument allows the government in our model with realistic wage distribution to design a flexible transfer system. In particular, it creates a distribution of replacement rates in the economy. We refer to the weighted average of those replacement rates as the effective replacement rate. Second, since we emphasize the role of UI as redistributing resources from high-wage to low-wage workers we also include a progressive tax system. This allows us to show that UI plays a role even when intensive progressive transfers are present in the model. In what follows we explain how those polices drive our main result given the exogenous heterogeneity in our model.

The point of departure of our quantitative analysis is a model where we shut down exogenous heterogeneity in income and unemployment rates by eliminating both skill types and individual productivity shocks. In this model the optimal UI policy is relatively stingy with a low effective replacement rate of $10 \%$. This echoes the finding in KMS, who highlight the tension between BHA and DMP type of models. On the one hand, the fact that workers cannot insure idiosyncratic risks, as in many models in the BHA framework, implies ex-post heterogeneity in consumption even among ex-ante identical workers. Absent any costs of reallocation, these models typically call for a high level of unemployment benefits, in order to equalize consumption among workers. On the other hand, the search and matching friction places an incentive cost of UI on labor demand. Specifically, in the DMP framework wages are determined by Nash bargaining, hence a more generous UI system improves workers' outside options, increases wages, and depresses firms' incentives to maintain vacancies. Therefore, more generous UI benefits imply higher unemployment rate and lower output. In fact, in a typical version of the DMP model where workers are risk-neutral and the (Hosios) efficiency condition holds, this model calls for no unemployment benefits. Similar to KMS, without exogenous heterogeneity the costs of UI clearly outweigh the 
benefits.

In contrast, our model with exogenous heterogeneity calls for a much higher effective replacement rate of 54\%. Given that our model includes exogenous heterogeneity both across and within skill types we consider them separately. In the version of the model where only skill types exist, workers differ in both productivity and separation rates. These differences create an endogenous distribution of unemployment rates and wages across types. As in the data, high skill is associated with higher wages and lower unemployment. The difference in wages generates consumption inequality that incentivises the policy maker to redistribute across workers. The difference in unemployment rates allows the government to do so, as low skill workers draw benefits at a higher frequency. In addition to this mechanism, the cap on unemployment benefits allows the government to provide low skill workers with a higher replacement rate. As both higher frequency and higher replacement rate work in favor of redistribution to low skill types, the government can use UI to redistribute resources across types. Indeed, the average effective replacement rate at the optimal policy is relatively high at $33 \%$.

The model where only individual productivity shocks exist illustrates the role of the cap more cleanly. In this model there are no differences in unemployment rates and therefore the frequency of drawing benefits is the same for everyone. However, given the empirical distribution of individual productivities, the cap implies a declining profile of effective replacement rates over productivity. Therefore, redistribution from high wage to low wage workers is still possible. The resulting average effective replacement rate at the optimal policy for this model is $43 \%$.

Our results highlight the redistributive role of UI even in the presence of a progressive tax system, yet it is possible that the calibrated tax system is not sufficiently progressive in two related dimensions. First, a more progressive general tax system may improve welfare. Second, a more progressive tax system can make the UI system redundant. We therefore extend our analysis to allow for a simultaneous choice of the general tax and the UI systems. The optimal general tax system is substantially more progressive and involves higher average tax relative to the benchmark. However, while the implementation of the optimal tax system makes the UI system less generous, it is far from eliminating it. The effective replacement rate implied by the optimal UI system is $44 \%$, and we show that similar patterns of redistribution through UI exist even if to a lesser extent.

This paper contributes to the optimal UI literature along two related dimensions. First, we show that an optimal UI system redistribute resources between high and low wage workers regardless of employment status. In doing so we contribute to the literature that strives at striking the right balance between insurance and incentives for insuring workers against unemployment shocks. Our 
model extends the concept of insurance to essentially include income and unemployment risks. Importantly, we also show that this dimension of insurance still exists in the presence of progressive taxation. Second, we emphasize the role of a cap on UI benefits in generating an effectively progressive unemployment benefits.

Our paper is related to a large body of literature on optimal UI, where a policy maker tradesoff insurance against incentives of workers and firms. Certain aspects of our analysis are closely related to a number of previous studies. Fredriksson and Holmlund (2001), Reichling (2007), KMS, and Mukoyama (2013) analyze UI in various contexts and model the incentive cost of UI through firm's incentives to post vacancies. However, they abstract from exogenous heterogeneity. Mitman and Rabinovich (2015) and Jung and Kuester (2015) study the optimal provision of UI in the context of business cycles but abstract from ex-ante heterogeneity.

A few previous studies theoretically analyze the redistributive aspects of UI specific contexts. Wright (1986) characterizes a voting equilibrium in a model with heterogeneity only in employment prospects, no ability to save, and no incentive issues. He shows that under certain conditions, the median voter would use the UI system to insure the ex-ante "high-risk" workers. Marceau and Boadway (1994) consider redistribution between high and low skill workers in a Mirrleesian economy. They argue that using a minimum wage policy coupled with a UI system can be welfare improving because it resolves the informational constraints hence allows for redistribution towards low skilled workers. In the law literature, Lester (2001) surveys some of the legal and policy aspects of UI, and describes some of the potential redistributive roles of UI.

Quantitative analysis of models with ex-ante heterogeneity along similar dimensions can be found in Pallage and Zimmermann (2001) and Mukoyama and Şahin (2006). Pallage and Zimmermann (2001) consider the question of optimal UI with ex-ante heterogeneity in skills. Their focus and analysis are different from ours due to the fact that the choice of UI generosity is based on political, or voting considerations, rather than welfare. Their results indicate that it is the voting that matters for the determination of optimal UI, regardless of whether workers are ex-ante homogeneous or heterogeneous. Mukoyama and Şahin (2006) consider the welfare consequences of business cycle fluctuations once skill differences are taken into consideration, and show that unskilled individuals experience a substantial cost associated with business cycle fluctuations. Finally, Conesa and Krueger (2006) analyze the optimal progressive taxation in a model with ex-ante heterogeneous households.

The rest of the paper is organized as follows. The model is presented in Section 2, and a detailed description of the calibration is in Section 3. Section 4 contains the quantitative analysis 
and the discussion of the results. In Section 5 we extend the analysis to a simultaneous choice of a UI system and a general progressive tax system. Concluding remarks are in Section 6.

\section{The model}

The model consists of a few central building blocks. First, workers' productivity is a combination of a fixed type-specific level, and draws of individual productivity from a stochastic process. Second, unemployment is a result of a search and matching friction in the labor market. Third, another dimension of heterogeneity arises endogenously from individual workers' asset accumulation decisions. Fourth, a standard neoclassical production function determines the level of output produced by each match. Finally, the government has two tax and benefit systems: (i) an unemployment insurance system that consists of a replacement rate, a cap on the level of maximum benefits, and a flat tax rate that balances that budget; (ii) a progressive tax system with lump sum redistribution.

We follow Krueger, Mitman, and Perri (2017) and assume that a constant fraction $\nu$ of workers dies every period and replaced by new workers of the same type. We assume that new workers are born unemployed with zero assets. Our analysis focuses on the stationary steady state of the model, thus we assume no aggregate risk. For comparability, where possible, we keep the notation of model description as close to KMS.

\subsection{Sources of Heterogeneity}

There is a measure one continuum of workers in the economy. We assume $N$ types of workers, where the fraction of type $i \in\{1, \ldots, N\}$ is $\phi_{i}$, and $\sum_{i} \phi_{i}=1$. The fraction of workers of each type is constant. Workers of type $i$ have type-specific separation rate $s_{i}$ and a recruiting $\operatorname{cost} \xi_{i}$. Productivity of workers, $z_{i} p$, is a product of a type-specific fixed effect $z_{i}$ and an individual level (within type) $p$, which follows an $\operatorname{AR}(1)$ process:

$$
\log \left(p_{t}\right)=\rho_{i} \log \left(p_{t-1}\right)+\epsilon_{t}
$$

where $\rho_{i}$ and $\sigma_{i}^{\epsilon}$ denote type specific persistence and standard deviation of the innovations. We assume that a new $\epsilon$ is drawn every employment period and when transitioning from unemployment to employment. A worker who transitions from employment to unemployment maintains his most recent $p$ throughout the unemployment spell. Newborns draw initial individual productivity from the invariant distribution of $p$. 
Another dimension of endogenous heterogeneity arises through asset accumulation. Workers can save and partially insure against unemployment risk by holding risk-free assets. In equilibrium, there exists a non-degenerate distribution of asset holding, as in BHA models.

Taken together, these sources of heterogeneity endogenously generate income and wealth differences across workers and unemployment rates differences across types.

\subsection{Matching and Market Tightness}

We assume that a worker's type is observable and that the labor market is segmented by types. Accordingly, firms maintain type-specific vacancies $\left(v_{i}\right)$, and unemployed workers apply only to vacancies that correspond to their type. Let $u_{i}$ denote the unemployment rate for type $i$, and assume that all unemployed workers search for jobs, such that the number of searchers in market $i$ is $\phi_{i} u_{i}$. A constant returns to scale matching function, $M\left(v_{i}, \phi_{i} u_{i}\right)$ determines the number of new type $i$ matches in a period.

We define market tightness in market $i, \theta_{i} \equiv v_{i} /\left(\phi_{i} u_{i}\right)$, as the ratio of the number of vacancies to the number of unemployed workers in market $i$. Thus, we denote the probability that a worker meets a vacant job by $\lambda_{i}^{w}=\lambda^{w}\left(\theta_{i}\right)$ where $\lambda^{w}$ is strictly increasing in $\theta$. Similarly, let $\lambda_{i}^{f}=\lambda^{f}\left(\theta_{i}\right)$ denote the probability that a firm with a vacancy meets an unemployed worker of the same type, where $\lambda^{f}$ is strictly decreasing in $\theta$.

A type $i$ match separates with constant and exogenous probability $s_{i}$ in each period. Matches that are formed in the current period become productive in the next period 11 Workers die with probability $\nu$ regardless of employment status and are replaced by unemployed workers of the same type. Firms treat the death of a worker as an exogenous separation. Denoting next period variables by a prime $\left(^{\prime}\right)$, the evolution of unemployment rate of type $i, u_{i}$, is

$$
u_{i}^{\prime}=\nu+(1-\nu)\left(\left(1-\lambda_{i}^{w}\right) u_{i}+s_{i}\left(1-u_{i}\right)\right)
$$

\subsection{Unemployment Insurance and Taxes}

There are two tax and transfer systems - UI and a general progressive tax.

The UI system consists of a replacement rate $h$ and a ceiling on the benefits $\kappa$. As long as under the cap, the UI benefit is a fraction $h$ of the average wage $\left(\bar{w}_{i}(p)\right)$ earned by employed

\footnotetext{
${ }^{1}$ Our model includes idiosyncratic productivity shocks thus allows endogenous separations. However, in our calibration such separations are never optimal. We therefore describe the model only with exogenous separations, to save on notation.
} 
workers of type $i$ and productivity $p 2^{2}$ We assume that UI is financed by a proportional tax $\tau^{U I}$ on labor earnings - wages for the employed, and unemployment benefits for the unemployed ${ }^{3}$ The government sets $\tau^{U I}$ in order to keep the budget of the UI system balanced.

In addition, the government collects income taxes according to the tax function suggested by Benabou (2002) and more recently used by Heathcote, Storesletten, and Violante (2017):

$$
T(y)=y-\lambda y^{1-\tau}
$$

where $y$ is the total flow income, which consists of wage or unemployment benefits, interest and dividend income, and $T(y)$ is tax paid. In this formulation $1-\lambda$ is the tax rate levied on a person who earns the average income and $\tau$ governs the degree of progressivity. For instance, if $\tau=0$ then the tax rate is flat at $1-\lambda$, and the system is progressive if $\tau>0$. Proceeds from this tax system are redistributed lump sum, denoted by $\Omega$.

\subsection{Asset Structure}

Workers have access to two types of assets: capital $(k)$ and claims on aggregate profits (equity, $x$ ). The pre-tax return on capital is the rental rate $r$ net of depreciation $\delta$. The pre-tax return on equity is $\frac{d+\pi}{\pi}$, where $d$ denotes dividends and $\pi$ denotes the price of equity. Workers cannot hold claims on individual jobs, hence they cannot insure the idiosyncratic employment risk that they face.

A standard no-arbitrage condition implies that the returns on holding capital and equity are equal $]^{4}$ As a result, workers are indifferent with respect to the composition of the two assets in their portfolios. This allows us to track the pre-tax "total financial resources", $a \equiv(1+r-\delta) k+$ $(\pi+d) x$, as a single state variable for each worker. In addition, there exists an ad-hoc borrowing constraint $\underline{a}$.

\footnotetext{
${ }^{2}$ We use the average wage in order to avoid the need to keep track of workers' individual histories. Our model results in wage functions that have little variation in wages within $(i, p)$ pairs. We verify in all numerical exercises that within each type the lowest wage is never lower than the unemployment benefit.

${ }^{3}$ In the US, UI is financed by firms' payroll taxes according to "experience rating" - firms that layoff workers more frequently pay higher tax rates. However, as shown by Card and Levine (1994) and argued by Ratner (2013), the experience rating system in the US is imperfect. To simplify, we abstract from experience rating.

${ }^{4}$ As there is no aggregate risk, the equity price remains constant in equilibrium. In addition, we assume that the same tax rate applies to both dividend and capital income. Therefore: $\pi=\frac{d+\pi}{1+r-\delta}$.
} 


\subsection{Workers}

Let $W_{i}(a, p)$ denote the value function of an employed worker of type $i$, individual productivity $p$, who owns $a$ assets. Similarly, $U_{i}(a, p)$ denotes the value function of an unemployed worker of type $i$, individual productivity $p$, who owns $a$ assets. Workers' productivity level evolves according to Equation (1). They move between employment and unemployment according to the endogenous job finding rate $\left(\lambda_{i}^{w}\right)$, and the exogenous job separation rate $\left(s_{i}\right)$. Workers take both probabilities parametrically.

Workers' period utility is represented by an increasing and strictly concave function $u(c)$, and they discount future streams of utility by a discount factor $\beta \in(0,1)$. Utility depends on consumption $(c)$ only, and there is no disutility from labor, home production, or search cost. Therefore, all unemployed workers actively seek employment.

Workers allocate their available resources between consumption and accumulation of assets in order to maximize the discounted value of lifetime utility.

An employed worker begins a period with some level of assets $(a)$, earns the period wage $(w)$, pays UI and general taxes, and receives the lump sum transfer. The worker's wage - determined by Nash bargaining as explained below - is a function of the worker's type and asset holdings. Therefore, the beginning of period asset holdings $a$ is the endogenous state variable, and $p$ is the exogenous state variable of the problem. We follow Krueger, Mitman, and Perri (2017) in assuming that the assets of the deceased pay extra returns to survivors. Denoting the inverse of the gross real interest by $q \equiv \frac{1-\nu}{1+r-\delta}$, imposing the borrowing constraint, and taking the transition probabilities into account, we specify the employed worker's problem:

$$
\begin{aligned}
W_{i}(a, p)= & \max _{c, a^{\prime}}\left\{u(c)+\beta_{i}(1-\nu)\left[s_{i} U_{i}\left(a^{\prime}, p\right)+\left(1-s_{i}\right) \mathbb{E}\left[W_{i}\left(a^{\prime}, p^{\prime}\right)\right]\right]\right\} \\
\text { s.t. }: & \\
& c+q a^{\prime}=a+w_{i}(a, p)-w_{i}(a, p) \tau^{U I}-T\left(a \times \frac{r-\delta}{1+r-\delta}+w_{i}(a, p)\right)+\Omega \\
& a^{\prime} \geq \underline{a}
\end{aligned}
$$

where the argument in $T()$ is the flow taxable income for the general tax system. The flow asset income is $\frac{\nu+r-\delta}{1+r-\delta}$. However, we assume that the tax is levied only on the income generated by the worker's assets at the beginning of the period $\left(\frac{r-\delta}{1+r-\delta}\right)$, and not on the return realized due to death $\left(\frac{\nu}{1+r-\delta}\right)$.

An unemployed worker begins a period with some level of assets $(a)$, receives unemployment 
benefits $b_{i}(p)=\min \left\{h \bar{w}_{i}(p), \kappa\right\}$, pays UI and general taxes, and receives the lump sum transfer. Taking the transition probabilities into account, the unemployed worker's problem is

$$
\begin{aligned}
U_{i}(a, p)= & \max _{c, a^{\prime}}\left\{u(c)+\beta_{i}(1-\nu)\left[\left(1-\lambda_{i}^{w}\right) U_{i}\left(a^{\prime}, p\right)+\lambda_{i}^{w} \mathbb{E}\left[W_{i}\left(a^{\prime}, p^{\prime}\right)\right]\right]\right\} \\
\text { s.t. } \quad: & \\
& c+q a^{\prime}=a+b_{i}(p)-b_{i}(p) \tau^{U I}-T\left(a \times \frac{r-\delta}{1+r-\delta}+b_{i}(p)\right)+\Omega \\
& a^{\prime} \geq \underline{a}
\end{aligned}
$$

\subsection{Firms and Production}

There is a large number of firms that can potentially maintain vacancies of any type, as long as they pay the type-specific cost $\xi_{i}$. The value of maintaining a vacancy of type $i, V_{i}$, is

$$
V_{i}=-\xi_{i}+\tilde{q}\left[\left(1-\lambda_{i}^{f}\right) V+\lambda_{i}^{f}(1-\nu) \mathbb{E}\left[J_{i}\left(a^{\prime}, p^{\prime}\right)\right]+\lambda_{i}^{f} \nu V\right],
$$

where $V=\max \left\{V_{1}, V_{2}, \ldots V_{N}, 0\right\}$ because firms are free to choose between any of the $N$ types of vacancies and being inactive. In equilibrium, firms post new vacancies until $V_{i}=0$ for all $i$.

We assume that firms discount future profits by $\tilde{q}$ - the average marginal rate of substitution of equity owners, weighted by asset ownership in the economy. $5^{5}$ The expected value of a match to the firm depends on the expected wage it will pay, that in turn depends on the worker's asset holdings (a) and individual level productivity $(p)$. Therefore, the firm must form expectations regarding the $(a, p)$ pair it will be matched with.

In order to produce, a firm with a filled vacancy has to rent capital. Let $k_{i}(p)$ be the capitallabor ratio for matches of type $i$ and individual productivity $p$. We assume a standard neoclassical production function $f(k)$ with $f^{\prime}>0, f^{\prime \prime}<0$, such that a match of type $i$ and productivity $p$ produces $z_{i} p f\left(k_{i}(p)\right)$ units of output. With a frictionless capital market, all firms pay the same rental rate $r$, implying equal marginal products across firms.

The value of a filled job for a firm is the sum of the current period flow profits and the discounted continuation value:

$J_{i}(a, p)=\max _{k_{i}(p)}\left\{z_{i} p f\left(k_{i}(p)\right)-r k_{i}(p)-w_{i}(a, p)+\tilde{q}(1-\nu)\left[s_{i} V_{i}+\left(1-s_{i}\right) \mathbb{E}\left[J_{i}\left(a^{\prime}, p^{\prime}\right)\right]\right]+\tilde{q} \nu V_{i}\right\}$

\footnotetext{
${ }^{5}$ Equity owners face different tax rates due to progressive taxation hence they have different marginal rates of substitution. Also note that we assume that all workers hold equity and capital in the same proportion.
} 


\subsection{Wage determination}

As in many other papers in the DMP literature, including KMS, we assume that the wage is determined, period-by-period, by Nash bargaining. The resulting wage functions are solutions to the problems:

$$
\max _{w_{i}(a, p)}\left(W_{i}(a, p)-U_{i}(a, p)\right)^{\gamma}\left(J_{i}(a, p)-V_{i}\right)^{1-\gamma}
$$

where $\gamma \in(0,1)$ represents the bargaining power of the worker of any type.

Due to the type-heterogeneity the solution involves a separate wage function $w_{i}(a, p)$ for each type. Wages are also a function of asset holdings $(a)$ because the workers' value function depends on $a$.

We define the stationary equilibrium and describe the computational algorithm in the Appendix.

\section{Calibration}

In this section we describe the calibration of the model that is used for the numerical analysis. We first describe a set of standard parameters that are kept constant across types. Then we describe in detail the calibration of parameters that govern the heterogeneity in the model.

\subsection{Constant parameters across types}

As in KMS, we set one period to 6 weeks, the production function to $f(k)=k^{\alpha}$, the utility function to $u(c)=\log (c)$, and the borrowing constraint $\underline{a}$ to 0 . We choose $\alpha=0.3$ and $\delta=0.01$ to generate a capital share of 0.3 and investment-output ratio of $0.22 .^{6}$ We calibrate $\nu=0.00036$ to match the social security data on death probability for men in 2004 at age 43 (the mid point of our sample and roughly the mid point of the population we consider in the next section)..$^{7}$

We assume a Cobb-Douglas matching function for all types: $M\left(v_{i}, \phi_{i} u_{i}\right)=\chi\left(\phi_{i} u_{i}\right)^{\eta} v_{i}^{1-\eta}$ so that

$$
\lambda_{i}^{w}=\theta_{i} \lambda_{i}^{f}=\chi \theta_{i}^{1-\eta}
$$

where $\chi$ is the matching efficiency parameter.

\footnotetext{
${ }^{6}$ In steady state aggregate capital is constant hence investment in our model is equal to the replenishment of depreciated capital.

${ }^{7}$ Available at https://www.ssa.gov/OACT/STATS/table4c6_2004.html
} 
Summarizing the literature that estimates the elasticity parameter $\eta$, Petrongolo and Pissarides (2001) establish a range of 0.5 - 0.7. Using more recent data, Brügemann (2008) finds a range of $0.54-0.63$. In our benchmark calibration, we specify $\eta=0.6$ to be near the mid point of these ranges. We set the worker's bargaining power parameter $\gamma=\eta$. In a textbook DMP model, setting $\gamma=\eta$ guarantees that the allocation is constrained efficient, as this calibration satisfies the Hosios (1990) condition for efficiency and would imply zero unemployment benefits if utility is linear. It is important to stress that satisfying this condition in our model does not guarantee efficiency. As Davila, Hong, Krusell, and Rios-Rull (2012) show, BHA models are not generally efficient because of externalities involved in the accumulation of capital. We also note that given the incompleteness of the assets market in our model there are benefits for having insurance. Such benefits could potentially be achieved by setting $\gamma>\eta$, a point made by Mukoyama (2013).

In our benchmark calibration of the UI system we set the replacement rate $h=0.4$, i.e. a $40 \%$ replacement rate, as is typically used to describe the replacement rate in the US economy. We also set the ceiling on unemployment benefits $\kappa=1.18$, which amounts to a fraction of about $48 \%$ of the median wage in the model. This calibration is based on data on maximum benefits by state, which is available for the years 2000-2009.8 For each year, we calculate the level of maximum benefits for the median state. We use data from the Current Population Survey (CPS) to calculate the median weekly earnings for men who are either full or part time workers.9 The calibration target for $\kappa$ is the ratio of maximum benefits at the median state to median weekly earnings.

The parameters of the general income tax function are set to $\lambda=0.902$ and $\tau=0.036$ in accordance with the point estimates reported by Guner, Kaygusuz, and Ventura (2014), who use data from the U.S. Internal Revenue Service to estimate various tax functions. We use the estimates that are based on the most inclusive sample that consists of all households in their sample.

\subsection{Type-Specific Parameters}

For the analysis in this paper, we identify skill with education - we divide the labor force into four types: Less than high-school, High-school graduates, Some college, and Bachelor's degree and over, denoted $\{1,2,3,4\}$, respectively. The calibration of parameters relevant for unemployment differences is based on data from the CPS. The calibration of parameters that govern the differences

\footnotetext{
${ }^{8}$ see https://workforcesecurity.doleta.gov/unemploy/uilawcompar/

${ }^{9}$ We use data on men for consistency with our PSID sample, which is described below. The median weekly earnings are calculated as the weighted average of median weekly earnings of full time workers and part time workers.
} 
in productivity across types relies on data from the PSID 10 We use data from 1996 to 2014 for male labor force participants who are 25 years and older, reflecting the assumption that most people have made their education level choice by that age. Finally, the calibration of type-specific discount factors relies on wealth moments from the Survey of Consumer Finances (SCF), for the years 1998-2013. As in many equilibrium models, there is no one-to-one correspondence between a single parameter or a single set of parameters and a calibration target. However, we organize this section such that targets are associated with the parameters that mostly affect them.

\subsubsection{Labor Force and Unemployment}

The top row of Table 1 describes the share of each education type $\left(\phi_{i}\right)$, equal to the average share of each type in the labor force in CPS data over the sample period.

The average unemployment rates decline with skill and equal 8.7\%, 6.1\%, 4.8\%, and 2.8\% for types 1-4 equal, respectively. In the model, steady state unemployment rates are

$$
u_{i}=\frac{s_{i}+\nu-s_{i} \nu}{s_{i}+\nu-s_{i} \nu+\lambda_{i}^{w}(1-\nu)}
$$

As in other DMP models, this expression suggests that differences in unemployment rates across types can stem from different separation rates, different job finding rates, or both.

In order to determine which one is mostly responsible for the observed differences in unemployment rates we follow the approach described by Shimer (2012), which is based on analysis of stocks and correction for short term unemployment. Interestingly, the data suggest a clear pattern of declining separation (employment exit) and job finding probabilities with skills. ${ }^{11}$

Note that the differences in job finding rates alone would imply a counterfactual increasing pattern of unemployment with skill. Therefore, and to keep the model parsimonious, we calibrate the model such that in the benchmark calibration, the entire difference in unemployment rates between types is due to the variation in the job separation rate. Specifically, we target a single equilibrium job finding rate of 0.6 per six-weeks period, consistent with the average monthly job finding rate in the data. Then we compute the implied separation rates such that the unemployment

\footnotetext{
${ }^{10}$ We use the data from Blundell, Pistaferri, and Saporta-Eksten (2018). We thank Itay Saporta-Eksten for supplying the data set.

${ }^{11}$ The monthly separation probabilities from low to high skill types are: $3.3 \%, 2.1 \%, 1.6 \%$, and $0.8 \%$. The monthly job finding probabilities from low to high skill types are: 50\%, 45\%, 45\%, and 39\%. Elsby, Hobijn, and Şahin (2010) report similar findings using CPS data for all working age population. Contemporaneous with our work and using a very similar methodology, Cairo and Cajner (2013) document similar patterns across education groups.
} 
rate per type is consistent with CPS data. The resulting values of $s_{i}$ are described in the second row of Table 1 .

We use the set of zero profit conditions - one for each type of vacancies - to calibrate the recruiting cost parameters $\xi_{i}$ as follows. In order to set the job finding rate at 0.6 for all types, we normalize the values of $\theta_{i}$ to equal 1 for all types, and set the matching efficiency parameter $\chi$ to equal 0.6. Given the productivity levels $z_{i}$, the expected individual productivity, and the separation rates, we use the zero profit conditions to solve for $\xi_{i}$ such that $\theta_{i}=1 \forall i$. The resulting values of $\xi_{i}$ are described in the third row of Table 1 .

There is some empirical evidence supporting the result of vacancy costs that increase with education. Dolfin (2006) finds that the number of hours required for recruiting, searching, and interviewing workers depends on their education. Assuming that the skill of the workers engaged in recruiting is independent of the worker recruited, Dolfin (2006) finds that the cost of recruiting a high-school graduate is $50 \%$ higher than the cost of recruiting a lower skill worker, and that the cost of recruiting a worker with more than high-school education is $170 \%$ higher than the cost of recruiting a worker with less than high-school education. Barron, Berger, and Black (1997) report findings based on a variety of data sources, all clearly suggest that the cost of recruiting a worker increases in the worker's level of education 12

\subsubsection{Productivity Parameters}

To capture the differences in productivity parameters we use data on hourly wage from the PSID ${ }^{13}$ We restrict attention to male household heads who are 25 years or older, continuously employed, and have no missing data on wages or hours of work.

To calibrate the group fixed effects $\left(z_{i}\right)$ we compute the hourly wage for each person in every year, assign people to the appropriate education group, and compute the median hourly wage within an education group for a given year. The median wages are used to compute the "education premiums" in each year. The parameter values reported in the fourth row of Table 1 take into account the average wage premiums over all years in our sample, while keeping the weighted

\footnotetext{
${ }^{12}$ Cairo and Cajner (2013) calibrate their model such that the recruiting cost is proportional to workers' productivity, which is not the case in our calibration. One reason for consistency between the two calibration strategies is that in their model, Cairo and Cajner separate between recruiting cost and training cost, and argue that the latter is higher for high skilled workers. If we think about recruiting costs as inclusive of such training costs, then the pattern of our calibration is consistent with theirs.

${ }^{13}$ In DMP models with Nash bargaining the separation rate has an effect on the wage as well. However, our model results indicate that differences in productivity account for more than $98 \%$ of the wage variation across type. Therefore we use data on wages to calibrate the productivity process.
} 
Table 1: Calibrated type-specific parameters

\begin{tabular}{lcccc}
\hline \hline & $\begin{array}{c}\text { Less than } \\
\text { High-school }\end{array}$ & High-school & Some college & $\begin{array}{c}\text { Bachelor's degree } \\
\text { and over }\end{array}$ \\
\hline Population share $\left(\phi_{i}\right)$ & 0.1128 & 0.3059 & 0.2566 & 0.3247 \\
Separation rate $\left(s_{i}\right)$ & 0.0568 & 0.0384 & 0.0302 & 0.0170 \\
Vacancy cost $\left(\xi_{i}\right)$ & 0.5481 & 0.7295 & 0.8802 & 1.4242 \\
Productivity fixed effect $\left(z_{i}\right)$ & 0.7200 & 0.8615 & 0.9683 & 1.2527 \\
Productivity persistence $\left(\rho_{i}^{\epsilon}\right)$ & 0.9821 & 0.9821 & 0.9821 & 0.9821 \\
Productivity shock $\left(\sigma_{i}^{\epsilon}\right)$ & 0.5182 & 0.5182 & 0.5182 & 0.5182 \\
Discount factor $\left(\beta_{i}\right)$ & 0.9940 & 0.9947 & 0.9947 & 0.9961 \\
\hline \hline
\end{tabular}

average of ex-ante productivity equal to one.

To facilitate comparability across the various calibrations we discuss below, we choose identical persistence and standard deviation parameters for individual productivity ${ }^{14}$ These parameters are estimated as follows. First, we run a standard Mincer regression of $\log$ wages with standard controls, including education $\sqrt{15}$ Second, we use the regressions to predict the residuals and use the panel dimension of the sample to estimate a regression identical to Equation 1 . The point estimates for the AR(1) coefficient are based on a two year period hence in the fifth row of Table 1 we report the values that correspond to the model period of six weeks. Finally, we use the predicted residuals from the second regression to compute the standard deviation of the residuals. The reported values in the sixth row of Table 1 are converted to the model frequency and used as our calibration parameters for the standard deviation of idiosyncratic shocks.

\subsubsection{Discount Factors}

Heterogeneous discount factors have been used in conjunction with BHA models in order to generate more realistic wealth distributions. ${ }^{16}$ We introduce heterogeneity in discount factors across education groups in order to match differences in wealth between the groups in the data. The SCF reports (every three years) the median family net worth and provides a breakdown by education of

\footnotetext{
${ }^{14}$ For our baseline model, we verify that heterogeneity along these dimensions does not affect the results.

${ }^{15}$ Experience, experience squared, and dummies for year, state, marital status, and race.

${ }^{16}$ See, for example, Krusell, Mukoyama, Şahin, and Smith (2009) and Krueger, Mitman, and Perri (2017)
} 
household heads that accords with our four education groups. For each year where data is available, we normalize the median wealth of high school dropouts to 1 , and compute the median wealth ratios by education for each year. Our calibration targets are the averages of these premiums for the years 1998 to 2013: 2.9, 3.3, 12.0 for high school graduates, some college, and Bachelor's degree and over, respectively.

The four discount factors, reported in the last row of Table 1 , are chosen to reasonably match the three premiums. Together with the depreciation rate $\delta$ and the death rate $\nu$ the annual interest rate is $3.4 \%$. We discuss the model's results with regards to the wealth distribution in Section 4.1.

\section{Results: the UI System}

In this section we use the calibrated model to study the dual role of the UI system in the economy as insurance against unemployment and as an instrument for redistribution of resources from high wage to low wage workers. First, we show that the inclusion of individual productivity shocks and ex-ante heterogeneity results in substantially more dispersed wage and wealth distributions. Second, we demonstrate the costs of UI by looking at its effect on unemployment, capital, aggregate consumption, and GDP. Then we discuss the welfare criterion that we use to determine the optimal policy (or policies) throughout our analysis, and turn to analyzing the welfare effects of changing the UI policy parameters.

We implement the policy analysis by computing the stationary equilibrium for the benchmark calibration with a replacement rate $h=40 \%$ and a cap on unemployment benefits $\kappa=1.18$, as well as alternative economies with different combinations of $h$ and $\kappa$. For these alternative economies, the only parameter we adjust other than the cap and replacement rate is the tax rate that balances the government budget. To clarify the roles of UI in the model, we compare the results to those that are based on a model with ex-ante homogeneous workers, as well as calibrations where only some heterogeneity dimensions are present.

\subsection{Wages and wealth}

One motivation for considering additional heterogeneity dimensions in this context is to generate an economy with more realistically dispersed wages and wealth relative to a typical BHA economy with ex-post asset heterogeneity only.

Table 2 describes the effect of sources of exogenous heterogeneity on the wage distribution. 
Table 2: Wage moments

\begin{tabular}{lcccc}
\hline \hline & Data & $\begin{array}{c}\text { Benchmark } \\
\text { calibration }\end{array}$ & $\begin{array}{c}\text { Only individual } \\
\text { shocks }\end{array}$ & $\begin{array}{c}\text { No individual } \\
\text { shocks }\end{array}$ \\
\hline Wage premiums & & & & \\
Type 2 & $31 \%$ & $31 \%$ & NA & $31 \%$ \\
Type 3 & $56 \%$ & $56 \%$ & NA & $55 \%$ \\
Type 4 & $127 \%$ & $126 \%$ & NA & $125 \%$ \\
\hline Gini & 0.39 & 0.44 & 0.39 & 0.19 \\
\hline \hline
\end{tabular}

Notes: Wage premium for type $i$ is the ratio of median wage of type $i$ to the median wage of type 1 (high school dropouts), minus 1 . The Gini coefficient in the data column is the average of the yearly Gini coefficients in the PSID sample we use.

Column (1) shows the wage premiums and Gini coefficient in the PSID, Column (2) shows the same moments for our benchmark calibration, Column (3) describes the moments for a model with individual shocks only, while the last column describes the results of a model with all dimensions of heterogeneity other than individual shocks. As point of reference we note that a model with no exogenous heterogeneity (i.e. similar to KMS) has low Gini coefficient (0.05) and, by construction, no wage premiums. Individual productivity shocks contribute substantially to increasing the Gini coefficient of wages (0.39) due to the fact that the individual productivity process is highly persistent and contributes to high ex-post variation in wages. The results in the last column indicate that the existence of ex-ante heterogeneity is instrumental in generating the skill wage premiums. Further analysis, not described here for brevity, shows that ex-ante productivity $(z)$ is responsible for wage heterogeneity. Finally, it is worth noting that wages within type-productivity pairs are fairly inelastic with respect to assets ${ }^{17}$

Table 3 describes various moments of the wealth distribution in the data (Column 1), in our benchmark calibration (Column 2), and in a calibration without exogenous heterogeneity that resembles KMS (Column 3). The top panel shows that our benchmark calibration provides a fair match to the wealth ratios described in Section 3.2.3. The middle panel describes the share of wealth owned by quintiles. The data figures are taken from Krueger, Mitman, and Perri (2017), who show that the overall wealth at the hands of the bottom $40 \%$ of the economy is around $1 \%$. While our calibration does not match the data precisely, it is a substantial improvement over the

\footnotetext{
${ }^{17}$ Krusell, Mukoyama, and Şahin (2010) and Bils, Chang, and Kim (2011) present similar wage functions in similar frameworks. The low variability of wages within type-productivity pairs supports the simplification in characterizing unemployment benefits as a replacement rate times the average wage for a type-productivity pair.
} 
Table 3: Wealth moments

\begin{tabular}{lccc}
\hline \hline & Data & $\begin{array}{c}\text { Benchmark } \\
\text { Calibration }\end{array}$ & $\begin{array}{c}\text { No exogenous } \\
\text { Heterogeneity }\end{array}$ \\
\hline Wealth ratios & & & \\
Type 2 & 2.9 & 2.6 & NA \\
Type 3 & 3.3 & 3.2 & NA \\
Type 4 & 12.0 & 12.8 & NA \\
\hline \% share by & & & \\
Q1 & -0.2 & 0.4 & 4.7 \\
Q2 & 1.2 & 2.8 & 10.2 \\
Q3 & 4.6 & 10.6 & 16.3 \\
Q4 & 11.9 & 25.0 & 25.6 \\
Q5 & 82.5 & 61.2 & 43.2 \\
\hline & & & \\
Gini & 0.78 & 0.61 & 0.39 \\
\hline \hline
\end{tabular}

Notes: Wealth ratios is the ratio of median wealth of type $i$ relative to type 1 (high school dropouts). Share of aggregate wealth owned by quintiles of the wealth distribution. Data moments are taken from Table 1 of Krueger, Mitman, and Perri (2017).

model with no ex-ante heterogeneity. The bottom $40 \%$ hold $3.2 \%$ of wealth in our benchmark calibration and $14.9 \%$ in a model with ex-ante homogeneous workers. ${ }^{18}$

\subsection{Analysis of Steady States}

In our main set of experiments the benchmark economy corresponds to the calibration described in Section 3, with a replacement rate $h=40 \%$ and a cap on unemployment benefits $\kappa=1.18$. The alternative economies that we consider involve fixing all the parameters but the replacement rate, the cap, and the implied UI tax. We consider replacement rates in the range $[0.1,1]$ and caps in the range $[0.1,3.7]{ }^{19}$

In order to create a more generous UI system, a policy maker can increase the replacement rate up to the point where the cap binds for the entire population, or increase the cap in cases that it does

\footnotetext{
${ }^{18}$ Krueger, Mitman, and Perri (2017) achieve an even better fit for the quintiles. We adopt their approach of using individual productivities and death shocks. For computational reasons, our implementation of heterogeneous discount factors is at the type level and not an additional individual shock.

${ }^{19}$ Other than the benchmark, we consider 190 alternatives, with grids $h \in\{0.1,0.2 \ldots 1.0\}$ and $\kappa \in\{0.1,0.3 \ldots 3.7\}$.
} 
not bind for (at least) a fraction of the population. The costs of a more generous UI system follow the logic of the DMP model: it improves workers' outside option, increases wages, depresses firms' incentive to maintain vacancies, and increases unemployment. Lower employment leads to a decline in the demand of capital. Hence aggregate production is expected to decline as well.

Considering alternatives around our benchmark calibration illustrate this point. When we fix the replacement rate at $40 \%$ and raise the cap from 0.1 to 3.7 (the minimum and maximum values we consider) we observe a drop of $0.76 \%$ in capital, a GDP loss of $0.93 \%$, aggregate consumption decline of $0.36 \%$, and increase in unemployment rates in the range of $22 \%$ to $25 \%$ for the different types of workers. ${ }^{20}$ To gauge the magnitude of such a change in terms of generosity of UI, we calculate the effective replacement rate as the average individual replacement rates, weighted by type and individual productivity. Raising the cap from 0.1 to 3.7 increases the effective replacement rate from $6 \%$ to $40 \%$ (i.e. a non-binding cap for all individuals).

When we fix the cap at 1.1 and increase the replacement rate from 0.1 to 1 the effective replacement rate increases from $10 \%$ to $54 \%$. This lowers capital by $1.61 \%$, consumption by $0.35 \%$, and GDP by $0.93 \%$. The response of unemployment rates varies considerably across types as the point at which the cap becomes binding varies due to the level differences in wages. In this case, the unemployment rates increase by $27 \%, 18 \%, 14 \%$, and $7 \%$ for types $1-4$, respectively.

\subsection{A Welfare Criterion}

To study the choice of an "optimal" replacement rate, we adopt the welfare criterion used in KMS and Mukoyama and Şahin (2006), which also resembles that in Pallage and Zimmermann (2001). First, we define a benchmark economy, such as our benchmark calibration, and calculate its stationary equilibrium. We then consider alternative economies, where we fix all the parameters except those relevant for the policy question, and calculate their steady state equilibrium. For each alternative we calculate the individual (characterized by type, individual productivity, employment status, and asset holding) welfare gain or loss relative to the benchmark. This measure of individual welfare difference is characterized by $\lambda$, defined by:

$$
E_{0}\left[\sum_{t=0}^{\infty} \beta^{t} \log \left((1+\lambda) c_{t}\right)\right]=E_{0}\left[\sum_{t=0}^{\infty} \beta^{t} \log \left(\widetilde{c}_{t}\right)\right]
$$

\footnotetext{
${ }^{20}$ The increase in unemployment rate is from $7.45 \%$ to $9.15 \%$ for type $1,5.26 \%$ to $6.53 \%$ for type $2,4.22 \%$ to $5.27 \%$ for type 3 , and $2.53 \%$ to $3.14 \%$ for type 4 .
} 
where $c_{t}$ is consumption under the benchmark and $\widetilde{c}_{t}$ is consumption under an alternative.

Finally, for each alternative economy we sum over the individual $\lambda$ s according to the distribution in the benchmark economy. This results in a measure of the aggregate welfare gain, where a positive aggregate gain is considered preferable over the benchmark. We refer to the policy with the highest aggregate gain as the "optimal" replacement rate and cap pair. This welfare criterion is preferable over summing steady state welfare levels for the different economies because a plain steady state comparison would miss the potentially important consequences of the short run savings adjustments along the transition to a new steady state. While admittedly we do not consider the entire transition path for all our results, in Section 4.7 we show that the main result is insensitive to whether or not the full transition path is taken into account: the welfare gain associated with shifting to the optimal policy is similar, and the optimal policy dominates alternative policies in its neighborhood.

A few issues regarding the welfare criterion warrant discussion. First, as pointed by Mukoyama (2010), this welfare criterion favors policies that redistribute resources from rich to poor individuals. This property of the welfare criterion is central to our analysis as we associate more inequality with stronger motivation to redistribute towards equality.

Second, and related to the first point, the welfare function operates over equivalent consumption rather than wealth. This is important because it is not wealth per se that matters for the policy maker but rather the present discounted value of each individual, which is composed of both wealth and human capital. Mukoyama (2010) describes this point in more detail.

Third, note that the optimal choice is determined by the total gain. In this respect, our choice is consistent with the analysis in KMS, but departs from the analysis in Pallage and Zimmermann (2001) that considers voting patterns, and therefore emphasizes the fraction of population that gains from a change in UI policy.

\subsection{The Optimal UI system}

In this section we present the results of a series of experiments where the sources of policy variation are the replacement rate, the cap, and the implied UI tax. First, we describe the optimal policy based on the benchmark calibration of our model with ex-ante heterogeneity as described in Sections 2 and 3. Then we describe the optimal policy for a model that is similar to KMS, where there is no exogenous heterogeneity ${ }^{21}$ The two models imply dramatically different policy prescrip-

\footnotetext{
${ }^{21}$ This model is essentially KMS with progressive taxes. When we consider ex-ante homogeneous workers, we calibrate the model such that the productivity level, the separation rate and the discount rate are all equal across types.
} 
tions. In order to understand what drives the large differences between the policy prescriptions, we gradually introduce the components that differentiate the two models. For each model we set the benchmark to have a replacement rate of $40 \%$ and a cap $\kappa=1.18$, and consider alternative pairs of replacement rate and cap such that $h \in[0.1,1]$ and $\kappa \in[0.1,3.7]$. Table 4 summarizes the results across models.

Our benchmark model suggests that welfare peaks at $h=1$ and $\kappa=1.1$ - an optimal policy that pays the minimum between the cap and the average wage per type-productivity pair. At the optimum, the effective replacement rate is $54 \%$, as opposed to $34 \%$ in the benchmark. In this respect, the optimal UI system is more generous relative to the benchmark. The welfare effects are non-negligible. For instance, switching from the benchmark to the optimal UI system results in a welfare gain in $0.41 \%$, while pushing the replacement rate and cap to their minimum possible levels generates a welfare loss of $0.15 \%$. By comparison, using the same welfare measure in a different context, Mukoyama and Şahin (2006) find an average welfare gain of $0.024 \%$ when eliminating business cycles.

In sharp contrast to the benchmark model, and consistent with the findings in KMS, the optimal policy in a model without exogenous heterogeneity workers calls for $h=0.1$ and $\kappa=0.1$, both at the bottom end of our experiments. The substantial difference in the optimal policy between the two models can stem from any of the differences between the two models: idiosyncratic productivity shocks $(p)$, ex-ante heterogeneity in discount rates $(\beta)$, separation rates $(s)$, and productivity $(z)$. We gradually introduce these features to the exogenously homogeneous model in order to better understand their effect on the optimal policy. For each of these "counterfactual" exercises, we recalibrate the model such that at $\{h=0.4, \kappa=1.18\}$ the economy reaches the same unemployment rate, median wage, and real return as in the calibration described in Section 32 We then search for the optimal policy by altering the replacement rate and the cap, where for each counterfactual, by construction, the welfare gain is zero at $\{h=0.4, \kappa=1.18\}$.

Departing from ex-ante homogeneity, we observe that heterogeneous discount factors have a modest effect on the optimal UI policy. The effective replacement rate increases to $10 \%$, close to the ex-ante homogeneous model and the results reported in KMS. Therefore, while heterogeneous discount factors are instrumental for matching data moments, they cannot explain the difference in optimal policy choice between ex-ante homogeneity and ex-ante heterogeneity. In contrast, the inclusion of either ex-ante differences in separation rates and productivity, or productivity shocks

\footnotetext{
${ }^{22}$ Clearly, certain data moments cannot be matched (e.g. wage dispersion without productivity differences, wealth dispersion without heterogeneity in discount factors, etc.)
} 
Table 4: Welfare gains, relative to $h=0.4, \kappa=1.18$ : various models

\begin{tabular}{lccc}
\hline \hline Model & Optimal RR & Optimal Cap & Effective RR \\
\cline { 1 - 1 } Benchmark & 1.0 & 1.1 & 0.54 \\
\cline { 1 - 1 } No exogenous heterogeneity & 0.1 & 0.1 & 0.04 \\
Add $\beta$ & 0.1 & 0.3 & 0.10 \\
Add $\beta, \sigma, z$ & 0.5 & 0.7 & 0.33 \\
Add $\beta, p$ & 1.0 & 0.9 & 0.43 \\
\hline \hline
\end{tabular}

appears to have a substantial effect on the optimal design of UI policy. The findings reported in the last two rows of Table 4 indicate that for both models the optimal UI policy is significantly more generous relative to the ex-ante homogeneous case. In what follows we argue that UI redistributes income from high wage workers to low wage workers, and that this is a key reason for the increasing generosity when moving from the model with no exogenous heterogeneity towards the benchmark model.

\subsection{The Redistributive Role of UI}

The goal of redistributive policies is lowering consumption dispersion. Simply put, had redistribution been costless, and given the fact that the welfare criterion favors equality, a policy maker would prescribe the same level of consumption to all workers. In our model we note three important features. First, using UI is costly, as illustrated by higher unemployment, lower capital, lower GDP, and lower aggregate consumption. Second, there is heterogeneity in consumption across types that may justify some degree of reallocation. Finally, there is also heterogeneity within type, due to individual productivity shocks. This fact may increase the gains from redistributing resources between workers in the economy, according to the welfare criterion. With this, our interpretation of the results is that given that UI is costly, the optimal policy is affected by the gains from redistribution and the ability to use the UI system to redistribute resources.

As an illustration of the effect of UI on consumption dispersion, we note that the Gini coefficient for steady state consumption equals 0.29 when the cap and replacement rate are at the minimal levels, 0.28 when using the calibration described in Section $3\{h=0.4, \kappa=1.18\}$ and 0.27 when switching to the optimal policy $\{h=1, \kappa=1.1\}$.23

\footnotetext{
${ }^{23}$ The corresponding Gini coefficients for consumption equivalents are $0.182,0.180,0.177$ hence demonstrating a similar pattern. These values are proxies for dispersion in terms of welfare, and have lower values due to the concavity
} 
Table 5: Welfare gains by type, relative to $h=0.4, \kappa=1.18$

\begin{tabular}{lccccc}
\hline Change policy to & Aggregate & Type 1 & Type 2 & Type 3 & Type 4 \\
\hline$h=1.0, \kappa=1.1$ & 0.41 & 1.57 & 0.64 & 0.29 & -0.12 \\
$h=0.1, \kappa=0.1$ & -0.15 & -0.98 & -0.38 & -0.14 & 0.34 \\
\hline \hline
\end{tabular}

To capture the heterogeneous effect of the UI system across types, we start by describing the differences in welfare gains and losses across types in the benchmark model. Table 5 reports the welfare gains by type, and illustrates that aggregate welfare masks a substantial variation in gains and losses between types. For example, implementing the optimal policy implies a welfare gain of $1.57 \%$ for type 1 and a welfare loss of $0.12 \%$ for type 4 . On the other hand, moving to the least generous UI system results in a welfare loss of $0.15 \%$ for type 1 and a welfare gain of $0.34 \%$ for type 4.

Table 6 describes the channels of redistribution across types that occur in the model. We begin with a calculation of the implied net transfer (UI benefits minus taxes paid to the UI system) for an average worker of each type. In general, we observe that type 4 workers are net payers while type 1 workers are net recipients ${ }^{24}$ This pattern is a result of two forces in the model. First, type 1 workers are unemployed more frequently hence they draw resources from the system more frequently. Second, the existence of a cap on UI benefits implies a declining profile of effective replacement rates over types, as the cap is more likely to bind for workers with higher wages. Moving to the optimal UI system intensifies the differences in net transfers, mainly between the highest group and the lowest two groups. For instance, when the UI system is minimal, the average type 4 workers pays 0.003 to the system while type 1 and type 2 workers receive 0.004 and 0.002 , respectively. These transfers are an order of magnitude larger under the optimal policy. As a point of reference the median wage in the economy is 2.45 .

Comparing the optimal policy to the benchmark calibration we observe that the effective replacement rate is not only higher for all types, but also demonstrates more progressivity. As the welfare metric favors lower dispersion, more equality across types is one justification for the optimal policy even though the economy has higher unemployment, and lower output, capital, and consumption.

The cross-type effects operate in a similar way in the version of the model that has no indi-

of the utility function.

${ }^{24} \mathrm{Net}$ transfers in the model always sum to zero. The reason that the numbers in the table do not sum to zero is the non uniform population weights. 
Table 6: Implications of UI policies

\begin{tabular}{lcccc}
\hline \hline & Type 1 & Type 2 & Type 3 & Type 4 \\
\hline \hline Effective replacement rate & & & & \\
$h=1.0, \kappa=1.10$ & 0.66 & 0.56 & 0.52 & 0.40 \\
$h=0.4, \kappa=1.18$ & 0.37 & 0.35 & 0.34 & 0.30 \\
$h=0.1, \kappa=0.10$ & 0.06 & 0.05 & 0.05 & 0.04 \\
\hline Net transfer & & & & \\
$h=1.0, \kappa=1.10$ & 0.061 & 0.022 & 0.001 & -0.044 \\
$h=0.4, \kappa=1.18$ & 0.033 & 0.015 & 0.003 & -0.029 \\
$h=0.1, \kappa=0.10$ & 0.004 & 0.002 & 0.002 & -0.003 \\
\hline \hline
\end{tabular}

vidual productivity shocks, but has all other dimensions of ex-ante heterogeneity. In that model the optimal UI system $\{h=0.5, \kappa=0.7\}$ generates an effective replacement rate of $33 \%$ and a declining profile across types. Therefore UI achieves similar redistribution goals by increasing transfers to the lowest type on account of the highest productivity type. In this model, the differences in unemployment rates are sufficient to support a similarly generous (effective) replacement rate even when the cap never binds as lower types are more frequently unemployed and draw more resources from the UI system.

Another dimension of income heterogeneity exists within education types due to the persistent individual productivity shocks. The presence of such shocks in conjunction with the cap on UI benefits allows for an additional redistribution between high wage and low wage workers within type. We first note that a model with individual productivity shocks but without ex-ante differences in $\sigma$ and $z$ calls for a relatively generous UI system $\{h=1, \kappa=0.9\}$, as described in Table 4 .

The existence of a cap implies that the effective replacement rate is higher for low productivity workers, for whom the cap is less likely to bind. As a result, the UI system generates redistribution even absent differences in unemployment rates due to the negative correlation between the effective replacement rate and the wage. For example, when $\{h=0.4, \kappa=1.18\}$ the highest productivity worker pays 0.037 and the lowest productivity worker receives 0.005 . These transfers increase to 0.052 and 0.031 when switching to the optimal policy. Interestingly, in this model (with just productivity shocks), if we set the cap to be at a level such that it never binds, then the optimal policy calls for a very low replacement rate $(h=0.1)$. This is due to the fact that since there are no differences in unemployment rates, and as the cap never binds, the UI system can no longer be used to redistribute resources. 
Taking stock, we conclude that both individual productivity shocks and ex-ante productivity differences across types generate income and consumption inequality hence potential welfare gains from redistribution. UI achieves two dimensions of redistribution. Redistribution within types is possible due to differences in effective replacement rates that are induced by the cap. Redistribution across types is possible due to variation in both unemployment rates and effective replacement rates.

\subsection{Disentangling the roles of UI}

Our analysis thus far suggests that in our model UI has a redistributive role beyond the standard insurance role. Furthermore, judging by the results of the model with ex-ante homogeneous workers, it appears that the insurance role is relatively small, while heterogeneity allows for redistribution using UI. To shed more light on the quantitative importance of insurance and redistribution we discuss three aspects of the consumption differences associated with moving from the benchmark policy $\{h=0.4, \kappa=1.18\}$ to the optimal one $\{h=1.0, \kappa=1.1\}$.

This thought experiment is consistent with our welfare analysis in the sense that we calculate the consumption difference for each worker when moving from an economy with the benchmark policy (with his employment status, asset position, and individual productivity) to an economy with the optimal policy. We first note that under this hypothetical experiment, when aggregating over the entire population there is a positive consumption gain and the average person in the economy increases his consumption by 0.015 units ( $0.4 \%$ of average consumption at the benchmark). This gain is a manifestation of the higher aggregate accumulation of assets under the benchmark policy relative to the optimal policy accompanied by a higher interest rate as well as higher wages for most workers. Similar to the welfare analysis, the average consumption gain masks an important distribution of gains that demonstrates the different roles of UI.

Comparing the employed to the unemployed we observe that an average unemployed worker would experience a consumption increase of 0.062 units while an employed worker gains 0.013 units. These average increases could be interpreted as the standard insurance effect of the more generous UI system. However, these gains are not equally distributed over the wealth distribution. The left panel of Figure 1 breaks down the average gains by employment status and quintiles of asset holdings. This panel shows that workers at the lower quintiles experience a greater level increase in their consumption. Moreover, the highest quintile of both employed and unemployed workers actually experience a decline in their consumption. We interpret these result as an indication for both insurance and redistribution. First, the fact that the unemployed experience a greater 
Figure 1: The Effect of UI on Consumption
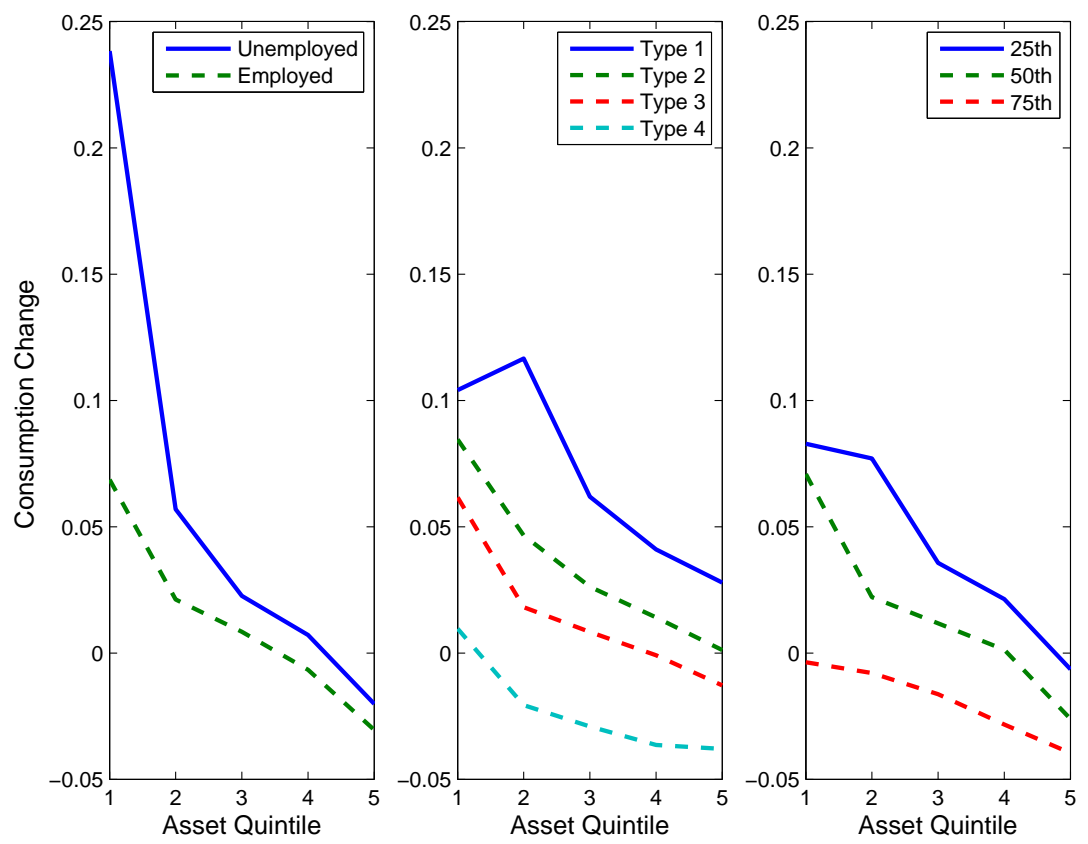

Notes: Change in consumption levels when changing the UI policy from the benchmark policy $\{h=$ $0.4, \kappa=1.18\}$ to optimal $\{h=1, \kappa=1.1\}$, by asset quintile. Results based on the consumption policy functions. Left panel: by employment status; Middle panel: by education type; Right panel: by percentiles of individual productivity.

increase in their consumption relative to the unemployed across all quintiles illustrates the typical insurance role of UI. Second, the fact that those differences are not uniform over asset quintiles illustrates a typical redistribution from the asset-rich to the asset-poor. In our model lower asset bins have a larger proportion of low education types and low individual productivity workers ${ }^{25}$ Therefore, the redistribution from asset-rich to asset-poor is effectively a redistribution along those two dimensions.

The two right panels of Figure 1 illustrate this point. In the middle panel we repeat the same exercise for the four eduction types. This panel shows that lower types experience a greater consumption increase for all asset quintiles, where the gains and losses are of the same order of magnitudes as those in the left panel[ ${ }^{26}$ In the right panel we repeat this exercise again but this time using the 25th, 50th and 75th percentiles of the individual productivity distribution. This panel

\footnotetext{
${ }^{25}$ Table 3 shows the wealth of types $2-4$ is $2.6,3.2$, and 12.8 times the wealth of type 1 . In addition, a worker at the 75th (50th) percentile of the individual productivity distribution holds 3.55 (1.78) times the assets held by a worker at the 25 th percentile.

${ }^{26}$ The average consumption differences by type are $0.071,0.035,0.015$ and -0.023 for types $1-4$, respectively.
} 
shows another clear pattern of redistribution, this time across productivity, reflecting redistribution from high-wage to low-wage workers. 27

Taken together, the three panels show an elaborated transfers scheme, which consists of both insurance against unemployment and important channels of redistribution. Moreover, while unemployment is a rather transitory state in the model, productivity is far more persistent and eduction types are permanent, explaining why these dimensions of exogenous heterogeneity have a dramatic effect on the optimal UI in Table 4.

\subsection{Transition Dynamics}

Our analysis so far, including the welfare gain, has focused on a steady state analysis between the benchmark policy and any alternative policy. We emphasized that our welfare criterion takes into account the complete distribution of assets, employment status and individual productivity at the benchmark. Therefore, no resource instantly appears or evaporates (including employment matches) in the transition. What is neglected, however, is the complete transition of prices along the path. In particular, the implied assumption in our analysis is that prices immediately adjust. Mukoyama (2013) discusses this in detail for a simpler, yet closely related, general equilibrium incomplete market model and provides a comprehensive analysis for the various moving parts along the transition path.

In this section we test the importance of this assumption for the main result. Our analysis of the transition closely follows that of Mukoyama (2013), and we refer the interested reader to that paper. Here we briefly explain the concept of the transition. An unexpected and permanent change in the policy is announced while the economy is in its original steady state. Following that change, both prices and quantities change endogenously according to the optimal decisions of both workers and firms. The transition is allowed to continue until the economy reaches a state that is sufficiently close to the steady state after the reform. Then, the welfare gain (or loss) is computed according to the difference in the value of workers in the period immediately following the reform to one period before.

We perform the transition path for the change from the benchmark economy $\{h=0.4, \kappa=$ $1.18\}$ to the optimal one $\{h=1.0, \kappa=1.1\}$. Figure 2 shows the transition path for capital and unemployment over the transition path of 150 model periods (about 17 years). The top panel shows that capital changes slowly over the transition path. This is related to the desire of workers

\footnotetext{
${ }^{27}$ For completion, the average consumption differences are $0.046,0.016$ and -0.019 for the 25 th, 50 th and 75 th percentiles, respectively.
} 
Figure 2: Tranisiton path: capital and unemployment
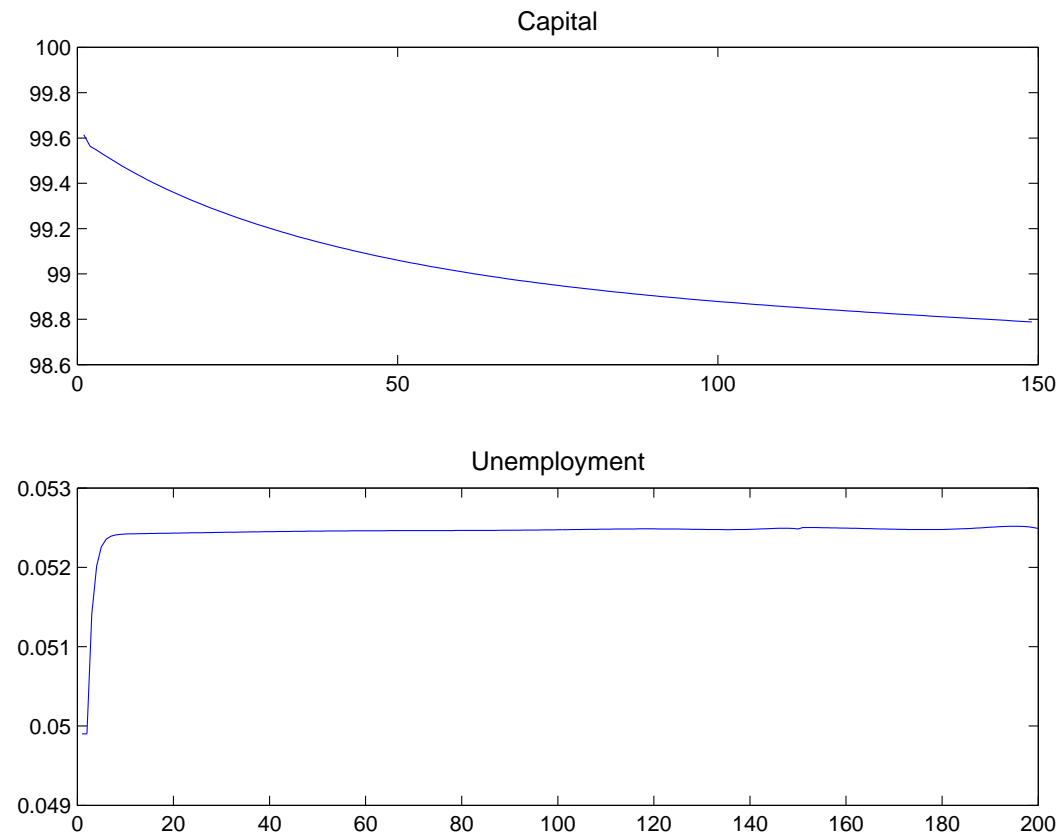

to smooth consumption over time. The bottom panel shows the dynamics of unemployment. Given that the value of unemployment increases upon the change in UI, wages immediately increase, the value of firms decreases and therefore vacancy creation declines. The fast adjustment of vacancies and job finding rates implies then that the change in employment rate is relatively quick. ${ }^{28}$

Comparing the welfare gains with and without the transition path, shows that the differences in the average welfare again as well as the type specific ones are very small ${ }^{29}$ In fact at the level of precision used in Section 4.5 (e.g., the first line in Table 5) there is no change at all in those figures. To further confirm this result we repeat the transition path exercise for UI policies in the neighborhood of the optimal policy. Specifically, we study the transition path for UI policies keeping the replacement rate at 1.0 as in the optimal policy and letting the cap vary in the set $\{0.5,0.7,0.9,1.3\}$, as well as keeping the cap at 1.1 as in the optimal UI and letting the replacement rate vary in the set $\{0.6,0.7,0.8,0.9\}$. In all those experiments we find that there is no meaningful

\footnotetext{
${ }^{28}$ Overall, the transition is very similar to that in Mukoyama (2013), who also shows wages, capital labor ratio and other statistics. We do not show those here for brevity of description and since many of our variables (e.g. wages) are multidimensional due to the various sources of heterogeneity in our model.

${ }^{29}$ This is in contrast to a naive comparison of steady states, which implies a much lower welfare gain of $0.17 \%$ as opposed to $0.41 \%$. This difference is a consequence of the inability of workers to consume the difference in assets along the transition path.
} 
difference in the welfare gain. We conclude that the welfare metric that we use (and that has been used in the literature) is a very reasonable approximation for the gain associated with the complete transition path in our model.

\subsection{Voting Patterns}

Given that the welfare criterion favors redistribution, we study whether the optimal policy is implementable in the sense of receiving sufficient support relative to the status quo. We address this by computing the fraction of workers in the economy who experience a positive welfare gain, regardless of its magnitude, when moving from the benchmark policy to the optimal one.

We find that $63 \%$ of the population support the policy change. The voting pattern among the types is generally consistent with the welfare gains reported in Table 5 . All workers of types 1 and $2,77 \%$ of type 3 , and only $5 \%$ of type 4 support the policy change.

In the model without ex-ante heterogeneity and with individual productivity shocks, UI has the ability to redistribute resources between high and low productivity types. In this context, because there is always a positive transition probability between productivity states, this redistribution essentially provides insurance against future productivity shocks. Therefore, it is not surprising that the optimal policy for this model, which involves a relatively generous UI system, receives unanimous support.

\section{Progressive Taxes}

In this section we extend our analysis by allowing for a flexible choice of the general progressive tax system. The results thus far indicate that UI serves as a mean for redistribution even in the presence of a progressive tax system, as calibrated in Section 3. However, it is possible that the calibrated tax system is not sufficiently progressive in two related dimensions. First, given that the welfare criterion that we use favors redistribution from rich to poor, it is possible that a different choice of parameters for general taxation may improve welfare ${ }^{30}$ Second, a more progressive tax system can make the UI system redundant.

The level and progressivity of the general tax system in the model are governed by the two parameters of the tax function described in equation 2. Specifically, $1-\lambda$ determines the tax rate levied on a worker who earns the average income in the economy, and a higher $\tau$ increases the

\footnotetext{
${ }^{30}$ See, for example, Conesa and Krueger (2006) and Heathcote, Storesletten, and Violante (2017).
} 
Figure 3: Tax Functions

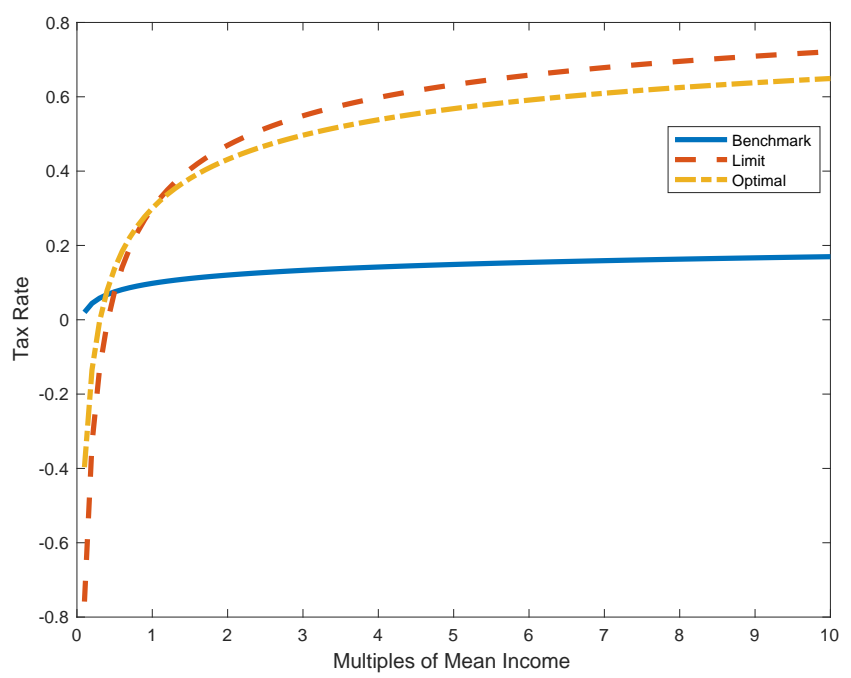

progressivity of the tax system around this point. We consider alternative tax systems that span over a relatively wide range: $\lambda \in[0.7,1]$ and $\tau \in[0,0.4]]^{31}$ The benchmark calibration of the tax function, as well as the one with the highest level $(\lambda=0.7)$ and progressivity $(\tau=0.4)$ (labeled as "Limit") are plotted in Figure 3. For each choice of a $(\lambda, \tau)$ pair, we consider the same 191 possible combinations of cap and replacement rate as in Section 4, and compare the welfare gains and losses relative to the calibration described in Section 3. This amounts to a choice of optimal policy over four parameters. The optimal combination over the policy grid is $\{\lambda=0.7, \tau=0.3, h=1, \kappa=0.7\}$.

The optimal general tax system (see Figure 3) is substantially more progressive relative to the benchmark model, as $\tau$ increases from 0.036 to 0.3 . Moreover, there is a level shift towards higher tax rates in the sense that the average income is taxed at $30 \%$ vs. $10 \%$ in the current benchmark. Not surprisingly, the implied lump sum transfer triples from 0.38 (or $8 \%$ of GDP) in the benchmark model to just over 1.16 (or $28 \%$ of GDP) under the optimal policy. The aggregate welfare gain implied by switching from the benchmark model to the optimal policy equals to $8.55 \%$. This high welfare gain is another indication for the fact that the welfare criterion favors redistribution, as the optimal policy also involves a lower Gini coefficient for consumption (0.19 instead of 0.29) but at a cost of a substantial drop in GDP (11\%) and aggregate consumption (5\%). ${ }^{32}$

\footnotetext{
${ }^{31}$ When $\lambda=1$ and $\tau=0$ there are no taxes. When $\lambda=0.7$ the tax rate levied on the average income is $30 \%$.

${ }^{32}$ Conesa and Krueger (2006) make a similar point with regards to a proportional tax system and a welfare criterion that sums steady state values.
} 
While the substantial change in tax policy has an effect on the optimal UI policy, it is far from eliminating it. In fact the optimal UI system involves a replacement rate of $h=1$ and a cap that equals $\kappa=0.7$, implying an effective replacement rate of $44 \%$. This also indicates that a significant fraction of unemployed workers receive payments that are of the same order of magnitude as the lump sum transfer (1.16). In addition, for all the general tax policies that we consider, the associated optimal UI policies involve an effective replacement rate of $40 \%$ or higher.

To evaluate the welfare gains from the existence of a UI system we consider all the candidate tax systems that are "more progressive" than the benchmark, i.e. $\lambda \leq 0.902$ and $\tau \geq 0.036$. We proxy the value of UI for each tax system as the difference between the welfare gain of its optimal UI and the welfare gain of the minimal UI $\{h=0.1, \kappa=0.1\}$. The results in Table 5 imply a value of UI of 0.56 for the benchmark tax system. As expected, when $\{\lambda=0.7, \tau=0.3\}$ the same metric yields a lower yet meaningful value of UI (0.28). Generally, the optimal UI policies generate values of UI in the range of $0.25 \%-0.56 \%$.

Turning to the insurance and redistributive roles of UI, first note that under the optimal system net transfers through UI are very similar to their values in the benchmark calibration 33 In addition, the more generous lump sum transfer associated with the optimal tax system narrows the consumption gap between the employed and unemployed even when the UI system is set to $\{h=0.1, \kappa=0.1\}$. Specifically, depending on type, workers lose 5.7\% - $6.2 \%$ upon unemployment under the benchmark tax system, as opposed to $3.5 \%-4 \%$ under the optimal tax system.

In summary, our results indicate that the benchmark calibration of the tax system is indeed not progressive enough in the sense that the optimal involves a level shift as well as more progressivity. In addition, the shift towards a more progressive tax system generates substantial welfare gains. The more progressive tax system appears to mitigate both the insurance and the redistributive role of UI, but not completely, hence there are still meaningful welfare gains from implementing the optimal UI system. 34

\section{Concluding remarks}

In this paper we argue that the redistributive role of UI is qualitatively and quantitatively important. We demonstrate this using a general equilibrium incomplete markets model that assumes exoge-

\footnotetext{
${ }^{33}$ The net transfers for an average worker of type $1,2,3$ and 4 are $0.038,0.015,0.001$, and -0.028 , respectively. These figures are very similar to the ones reported in table 6 .

${ }^{34}$ Our findings echo the empirical results in Attanasio and Davis (1996). They find that the progressivity of the US tax system, as well as various welfare program, is still insufficient in providing cross-type consumption insurance.
} 
nous heterogeneity in productivity and separation rates, which results in heterogeneity in labor income and unemployment risk. We calibrate the model to match the considerable income dispersion and other key characteristics observed in US data, which also results in a realistic variation in consumption across workers. The quantitative implications are substantial: the average effective replacement rate is more than five times as large as in a model without exogenous heterogeneity, with lower income workers facing higher replacement rates.

This finding is an outcome of a number of features in our analysis. First, since lower wage workers also face greater unemployment risk these workers draw resources more frequently from the the UI system. Second, the existence of a cap on UI benefits implies an essentially progressive benefits schedule as the cap is more likely to bind for higher wage workers. Finally, the welfare criterion (often used in the literature) favors equality hence provides an incentive for a policy maker to use UI for redistribution.

Our main finding that UI has a redistributive role holds in the presence of the current progressive general tax and redistribution system. We therefore extend the analysis and allow for a simultaneous choice of both UI and general taxation. We find that the optimal general tax system should be far more progressive than its current state, and that the optimal choice mitigates the gains from redistribution through UI. However, the optimal choice is far from eliminating the UI system and its redistributive aspects. We believe that these findings present a promising and challenging avenue for future research regarding the optimal mix of redistributive policies. To conduct this type of analysis one has to enrich the current model along a few dimensions. First, to fully capture the distortions presented by progressive taxation, an active labor or hours supply should be added to the model. Second, more welfare programs that are potentially redistributive should be incorporated into the analysis. 


\section{References}

AiYAGARI, S. R. (1994): “Uninsured Idiosyncratic Risk and Aggregate Saving," The Quarterly Journal of Economics, 109(3), 659-84.

Attanasio, O., And S. J. Davis (1996): "Relative Wage Movements and the Distribution of Consumption," Journal of Political Economy, 104(6), 1227-62.

Barron, J. M., M. C. Berger, and D. A. Black (1997): “On-The-Job Training," W.E. Upjohn Institute for Employment Research Michigan, USA.

Benabou, R. (2002): "Tax and Education Policy in a Heterogeneous-Agent Economy: What Levels of Redistribution Maximize Growth and Efficiency?," Econometrica, 70(2), 481-517.

Bewley, T. F. (undated): “Interest Bearing Money and the Equilibrium Stock of Capital," Mimeo, 47(3), 895-936.

Bils, M., Y. Chang, And S.-B. Kim (2011): "Worker Heterogeneity and Endogenous Separations in a Matching Model of Unemployment Fluctuations," American Economic Journal: Macroeconomics, 3(1), 128-54.

Blundell, R., L. Pistaferri, and I. Saporta-Eksten (2018): “Children, Time Allocation, and Consumption Insurance," Journal of Political Economy, 126(S1), 73-115.

BRÜGEMANN, B. (2008): "What elasticity of the matching function is consistent with U.S. aggregate labor market data?," .

CAiro, I., And T. CAJner (2013): "Human Capital and Unemployment Dynamics: Why More Educated Workers Enjoy Greater Employment Stability," Finance and Economics Discussion Series 2014-9, Board of Governors of the Federal Reserve System (U.S.).

CARD, D., AND P. B. Levine (1994): "Unemployment insurance taxes and the cyclical and seasonal properties of unemployment," Journal of Public Economics, 53(1), 1-29.

Conesa, J. C., And D. KRUEGER (2006): "On the optimal progressivity of the income tax code," Journal of Monetary Economics, 53(7), 1425-1450. 
Davila, J., J. H. Hong, P. KRusell, And J.-V. Rios-Rull (2012): “Constrained Efficiency in the Neoclassical Growth Model With Uninsurable Idiosyncratic Shocks," Econometrica, 80(6), 2431-2467.

Diamond, P. A. (1982): "Aggregate Demand Management in Search Equilibrium," Journal of Political Economy, 90(5), 881-94.

Dolfin, S. (2006): “An examination of firms’ employment costs,” Applied Economics, 38(8), 861-878.

Elsby, M. W. L., B. Hobijn, And A. ŞAhin (2010): "The Labor Market in the Great Recession," Brookings Papers on Economic Activity, 41(1 (Spring), 1-69.

Fredriksson, P., AND B. Holmlund (2001): “Optimal Unemployment Insurance in Search Equilibrium," Journal of Labor Economics, 19(2), 370-399.

Guner, N., R. Kaygusuz, and G. Ventura (2014): "Income Taxation of U.S. Households: Facts and Parametric Estimates," Review of Economic Dynamics, 17(4), 559-581.

Heathcote, J., F. Perri, and G. L. Violante (2010): "Unequal We Stand: An Empirical Analysis of Economic Inequality in the United States, 1967-2006," Review of Economic Dynamics, 13(1), 15-51.

Heathcote, J., K. Storesletten, and G. L. Violante (2017): “Optimal Tax Progressivity: An Analytical Framework," The Quarterly Journal of Economics, 132(4), 1693-1754.

Hosios, A. J. (1990): “On the Efficiency of Matching and Related Models of Search and Unemployment," Review of Economic Studies, 57(2), 279-98.

HugGetT, M. (1993): “The risk-free rate in heterogeneous-agent incomplete-insurance economies," Journal of Economic Dynamics and Control, 17(5-6), 953-969.

Jung, P., And K. Kuester (2015): “Optimal Labor-Market Policy in Recessions,” American Economic Journal: Macroeconomics, 7(2), 124-156.

Krueger, D., K. Mitman, And F. Perri (2017): "Macroeconomics and Heterogeneity, Including Inequality," in Handbook of Macro Economics, vol. 2B, chap. 11. 
Krusell, P., T. Mukoyama, And A. ŞAhin (2010): "Labour-Market Matching with Precautionary Savings and Aggregate Fluctuations," Review of Economic Studies, 77(4), 1477-1507.

Krusell, P., T. Mukoyama, A. Şahin, and A. A. Smith (2009): "Revisiting the Welfare Effects of Eliminating Business Cycles," Review of Economic Dynamics, 12(3), 393-402.

LESTER, G. (2001): “Unemployment Insurance and Wealth Redistribution,” UCLA LAW REVIEW, 49(1), 335-393.

Marceau, N., And R. BoAdway (1994): "Minimum Wage Legislation and Unemployment Insurance as Instruments for Redistribution," Scandinavian Journal of Economics, 96(1), 6781.

Mitman, K., AND S. RABinOVich (2015): “Optimal unemployment insurance in an equilibrium business-cycle model," Journal of Monetary Economics, 71(C), 99-118.

Mortensen, D. T. (1982): "Property Rights and Efficiency in Mating, Racing, and Related Games," American Economic Review, 72(5), 968-79.

Mukoyama, T. (2010): "Welfare effects of unanticipated policy changes with complete asset markets," Economics Letters, 109(2), 134-138.

- (2013): "Understanding the welfare effects of unemployment insurance policy in general equilibrium," Journal of Macroeconomics, 38(PB), 347-368.

MukoyAmA, T., AND A. Ş AHIN (2006): “Costs of business cycles for unskilled workers,” Journal of Monetary Economics, 53, 2179-2193.

PAllage, S., And C. Zimmermann (2001): "Voting on Unemployment Insurance," International Economic Review, 42(4), 903-23.

Petrongolo, B., And C. A. Pissarides (2001): "Looking into the Black Box: A Survey of the Matching Function,” Journal of Economic Literature, 39(2), 390-431.

PISSARIDES, C. A. (1985): "Short-run Equilibrium Dynamics of Unemployment Vacancies, and Real Wages," American Economic Review, 75(4), 676-90.

RATNER, D. D. (2013): “Unemployment Insurance Experience Rating and Labor Market Dynamics," FEDS Working Paper, (2013-86). 
REICHLING, F. (2007): “Optimal Unemployment Insurance in Labor Market Equilibrium when Workers can Self-Insure,” MPRA Paper 5362, University Library of Munich, Germany.

SHIMER, R. (2012): "Reassessing the Ins and Outs of Unemployment," Review of Economic Dynamics, 15(2), 127-148.

WRIGHT, R. (1986): “The redistributive roles of unemployment insurance and the dynamics of voting," Journal of Public Economics, 31(3), 377-399. 


\section{A Stationary equilibrium}

In this appendix we describe the stationary equilibrium of the economy. For ease of notation and consistency with the computational method we describe a discrete state space. We use the notations $\operatorname{Pr}\left(p^{\prime} \mid p\right)$ as the transition probability of individual productivity, and $\operatorname{Pr}(p)$ as the unconditional probability for individual productivity draws. A stationary equilibrium consists of:

1. A set of value functions $\left\{W_{i}(a, p), J_{i}(a, p), U_{i}(a, p), V\right\}$

2. Consumption $c_{i}^{e}(a, p)$ and $c_{i}^{u}(a, p)$ for employed and unemployed workers, respectively, as well as asset accumulation policy functions $g_{i}^{e}(a, p)$ and $g_{i}^{u}(a, p)$

3. Prices $\left\{r, w_{i}(a, p), \pi\right\}$

4. Vacancies $v_{i}$ and demand for capital (per worker) $k_{i}(p)$

5. Tightness ratios $\theta_{i}$ and implied probabilities $\lambda_{i}^{w}$ and $\lambda_{i}^{f}$

6. A UI policy of replacement rate $h$, a ceiling on benefits $\kappa$ and a UI tax rate $\tau^{U I}$

7. A general tax policy $T(y)$ and lump sum transfers $\Omega$

8. Dividends $d$

9. Distributions over type $i$, employment status (either $e$ or $u$ ), assets $a$ and individual productivity $p$, denoted by $\mu_{i}^{e}(a, p)$ and $\mu_{i}^{u}(a, p)$

such that:

1. Given the job finding probability $\lambda_{i}^{w}$, the wage function, and prices $\{r, \pi\}$, the worker's choices of $c$ and $a^{\prime}$ solve the optimization problem for each individual. This results in the value functions $W_{i}(a, p)$, and $U_{i}(a, p)$.

2. Given the wage functions, prices, the distribution $\mu_{i}^{e}(a, p)$, and the workers asset accumulation decisions, each firm solves the optimal choice of $k_{i}(p)$. This results in $J_{i}(a, p)$.

3. Given the wage functions, prices, the distribution $\mu_{i}^{u}(a, p)$, the unemployed workers asset accumulation decisions, and the job filling probability $\lambda_{i}^{f}$, firms compute the value $V_{i}$. With free entry, $V_{i}=0$. 
4. The asset market clears, and the aggregate demand for capital equals supply.

5. The wage functions $w_{i}(a, p)$ are determined by Nash bargaining.

6. The government's UI system has a balanced budget.

7. The government's general taxation system has a balanced budget.

8. The dividend paid to equity owners every period is the sum of flow profits from all matches, net of the expenditure on vacancies. ${ }^{35}$

$$
d=\sum_{i}\left[\sum_{a} \sum_{p}\left[\left(z_{i} p f\left(k_{i}(p)\right)-r k_{i}(p)-w_{i}(a, p)\right) \mu_{i}^{e}(a, p)\right]-\xi_{i} v_{i}\right]
$$

9. The distributions $\mu_{i}^{e}(a, p)$ and $\mu_{i}^{u}(a, p)$ are invariant and generated by $\left\{\lambda_{i}^{w}, s_{i}, \nu, \phi_{i}\right\}$, the law of motion for individual productivity and the asset accumulation policy functions as follows:

$$
\begin{aligned}
\mu_{i}^{e}\left(a^{\prime}, p^{\prime}\right)= & (1-\nu)\left\{\left(1-s_{i}\right) \sum_{a} \sum_{p} \mu_{i}^{e}(a, p) \times \operatorname{Pr}\left(p^{\prime} \mid p\right) \times \mathbb{1}\left\{g_{i}^{e}(a, p)=a^{\prime}\right\}\right. \\
& \left.+\lambda_{i}^{w} \sum_{a} \sum_{p} \mu_{i}^{u}(a, p) \times \operatorname{Pr}\left(p^{\prime} \mid p\right) \times \mathbb{1}\left\{g_{i}^{u}(a, p)=a^{\prime}\right\}\right\} \\
\mu_{i}^{u}\left(a^{\prime}, p^{\prime}\right)= & (1-\nu)\left\{s_{i} \sum_{a} \mu_{i}^{e}\left(a, p^{\prime}\right) \times \mathbb{1}\left\{g_{i}^{e}\left(a, p^{\prime}\right)=a^{\prime}\right\}\right. \\
& \left.+\left(1-\lambda_{i}^{w}\right) \sum_{a} \mu_{i}^{u}\left(a, p^{\prime}\right) \times \mathbb{1}\left\{g_{i}^{u}\left(a, p^{\prime}\right)=a^{\prime}\right\}\right\} \\
& +\phi_{i} \times \nu \times \operatorname{Pr}(p) \times \mathbb{1}\left\{a^{\prime}=0\right\} \\
\phi_{i}= & \sum_{a} \sum_{p}\left(\mu_{i}^{e}(a, p)+\mu_{i}^{u}(a, p)\right)
\end{aligned}
$$

\section{B Computation}

In order to maximize her utility, the worker needs to know the entire wage function, $w_{i}(a, p)$. Therefore the algorithm we use aims at finding a functional fixed-point.

1. Start with an initial guess for $w_{i}(a, p), r, \theta_{i}$ and $\tau$.

\footnotetext{
${ }^{35}$ As flow profits depend on asset holdings of individual workers, this distribution is taken into account.
} 
2. Given the current guess for $\theta_{i}$, compute the probability of finding a job $\lambda_{i}^{w}$ for each type and the associated unemployment level $u_{i}$.

3. Solve the workers' dynamic programming problem for each type of worker and for each level of assets. This gives both the value function and the capital accumulation path.

4. Given the employee's capital accumulation path and the wage associated with her next period's assets, calculate the firm's value function for each type of employee and for each asset level. This does not require the asset distribution, which is calculated in the next step.

5. Based on the optimal saving decisions of workers and the transitions probabilities between employment and unemployment, as well as the transition probabilities across types, calculate the stationary distribution of assets for employed and unemployed workers of each type. Calculate the aggregate stationary distribution of workers across asset holdings given the weights $\phi_{i}$ of each group, the distribution of individual productivity $p$ and the measures of employed and unemployed workers within each group. This gives the total capital stock.

6. Update of the guess for $\left\{w_{i}(a, p), r, \theta_{i}, \tau\right\}$ as follows.

- Given the value functions of workers in step 3 and firms in step 4 perform Nash bargaining, which delivers an update for $w_{i}(a, p)$.

- Use the total capital stock from step 5, $u_{i}$ from step 2 and the first-order condition of each type of firm to compute $k_{i}$ and $r$.

- Use the firm's value and the distribution of assets over unemployed to calculate the expected value for the firm from a match. Given the vacancy cost and the value of a match we update $\theta_{i}$ such that the value of a vacancy is zero. Note that we do not force $\theta_{i}$ to be the same across types.

- Given $u_{i}, w_{i}(a, p)$ and the stationary distribution of workers across asset holdings of each type in step 5, update the tax rate so that the budget is balanced.

7. Repeat steps 2-6 until convergence is reached. 